\title{
Effects of Addition of Aluminum Oxide on Flexural Strength and Hardness of Acrylic Resins
}

\author{
Dr.Lavanya Pentapati, Dr.K.Srinivas, Dr.Y Ravi Shankar, Dr.V.Swetha, \\ Dr.M.Hari krishna
}

\begin{abstract}
:
Purpose: Acrylic dentures frequently fracture during service due totheir poor strength characteristics. The aim of this study was to evaluate the effects of adding 5\%, 10\% and 15\% aluminum oxide powder on the flexural strength, surface hardness of a conventional heat-polymerized acrylic resin.

Materials and methods: One of the commonly used conventional heat cure denture base resin (DPI) and high impact heat cure denture base resin(lucitone) with incorporation of three different percentage of aluminum oxide concentration was studied in 4 groups of 10 samples each.

A standard mould measuring $65 \times 10 \times 3 \mathrm{~mm} 3$ (ISO 1567 standard) was obtained for the fabrication of 40 specimens that were divided into 4groups; group-A was unmodified denture base resin (Control group), group$B$, group- $C$ and group-D were modified denture base resin with $5 \%, 10 \%$ and $15 \%$ by wt. aluminum oxide powder respectively.All specimens were stored in distilled water at $37^{\circ} \mathrm{C}$ for 7 days. The flexural strength of thespecimens was measured using 3-point bending test in a Universal Testing Machine.Hardness testing was conducted using shore hardness tester.

Conclusion: Reinforcement of the conventional heat-cured acrylic resin(DPI) and high impact heat cured acrylic resin(LUCITONE) with $15 \%$ by wt.\% Aluminum oxide powder significantly increased its flexural strength and hardness with no adverse effects.
\end{abstract}

Keywords: Conventional heat cure denture base resins; flexural strength; aluminum oxide powder,hardness.

\section{Introduction}

One of the most widely used materials in prosthetic dentistryis polymethyl methacrylate (PMMA). Since its introduction todentistry, it has been successfully used for denture basesbecause of its ease of processing, low cost, light weight, andcolor-matching ability $(1,2)$. However, acrylic resin denture basematerials have poor strength $(3,4)$.

Many attempts have been made to enhance the strengthof acrylic denture bases including the addition of metalwires and cast metal plates(5-7). The primary problem withusing metal wire is poor adhesion between the wire andresin(7).Although metal plates increase thestrength, they may be expensive and prone tocorrosion.

Mechanical reinforcement of acrylics has alsobeen attempted through the inclusion of fibers and metalinserts $(5,8)$.Although the inclusion of the fibersproduced encouraging results, this method has variousproblems including tissue irritation, increased productiontime, difficulties in handling, the need for precise orientation, and placement or bonding of the fibers within theresin $(1,9,10)$.

In the case of metal inserts, failure due to stressconcentration around the embedded inserts has beenreported. Although it has been reported that untreated aluminumoxide (A12O3) powder develops physical properties of highimpactacrylic resin(11-13),there have been no investigationsregarding the effect of A12O3 powder on the mechanicalproperties of a conventional heat-cured acrylic resin.Therefore, we evaluated the effects of $\mathrm{Al} 2 \mathrm{O} 3$ at threedifferent concentrations on the flexural strength (FS),surface hardness of a conventionalheat-cured acrylic resin and high impact heat-cured acrylic resin.

\section{Materials and Methods}

A custom tray made of self cure acrylicmaterial suitable for the stainless steel mold was fabricated. With thepolyvinylsiloxane impression material,an impression of this mold was made and master cast was poured with improved dental stonei.e. die stone (Kalrock). Modeling wax was placed in each of the compartment. Master cast was invested in the dental flask using dental stone following manufacturer's instructions. was carried out and mold was allowed to cool. A standard moldmeasuring $65 \times 10 \times 3 \mathrm{~mm} 3$ (ISO 1567 standard) was obtained for the fabrication of 40 specimens which were divided into 4 groups of 10 each. 


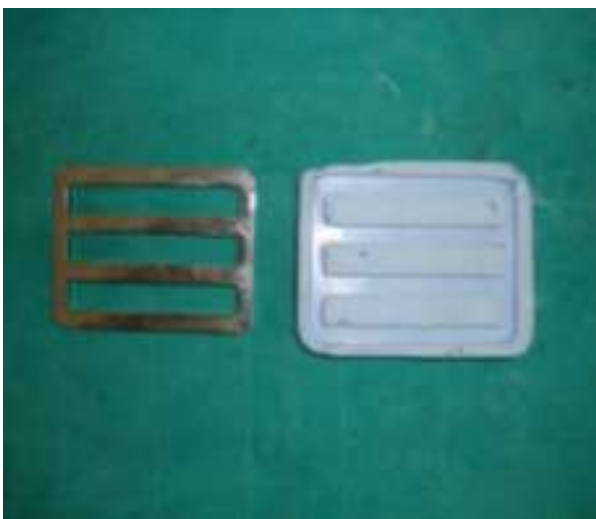

Fig A: stainless steel mold

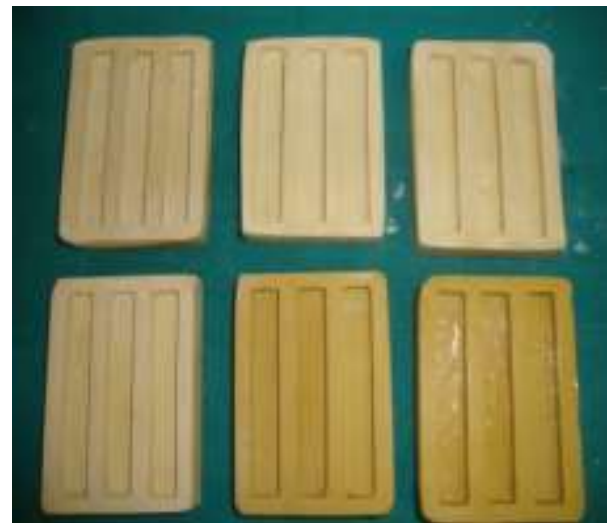

Fig B: master cast

About 40 specimens of DPI heat cure resin and 40 specimens of LUCITONE heat cure resin were divided into 4 groups each:

Group-A: Unmodified heat cure denture base resin(Control group).

Group-B: Modified heat cure denture base resin withaddition of $5 \%$ by wt. aluminium oxide powder.

Group-C: Modified heat cure denture base resin withaddition of $10 \%$ by wt. aluminium oxide powder.

Group-D: Modified heat cure denture base resin withaddition of $15 \%$ by wt. aluminium oxide powder.

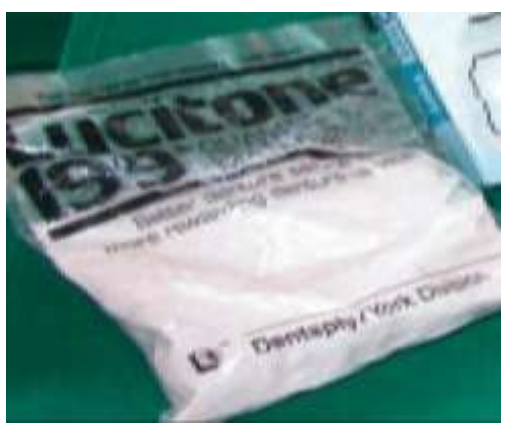

Fig C: Lucitone heat cure material

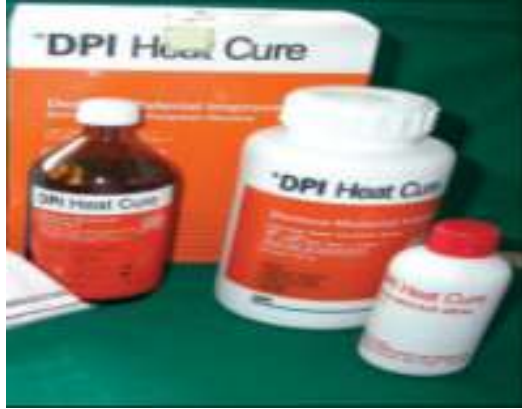

Fig D: DPI heat cure material

Three concentrations $(5 \%, 10 \%$ and $15 \%)$ of aluminum oxide powder(5-22 microns) were mixed with polymer.As per Ellakwa et al(12)andSehajpal et al(2), for an even distribution of filler withinthe polymer matrix, Aluminum oxide powderwasmixed with resinpowder and liquid monomer. The oxide powder andacrylic powder were thoroughly mixed using a mortar andpestle for initial mixing and blending, followed by handtumbling in a plastic jar until a uniform color is achieved. When the mix had reached doughstage, it was packed into the molds and the flask was kept inbench press unit for bench curing for 30mins and curing was done according to manufacturer'sinstructions.Specimens were stored indistilled water at $37^{\circ} \mathrm{C}$ for 7 days before test.
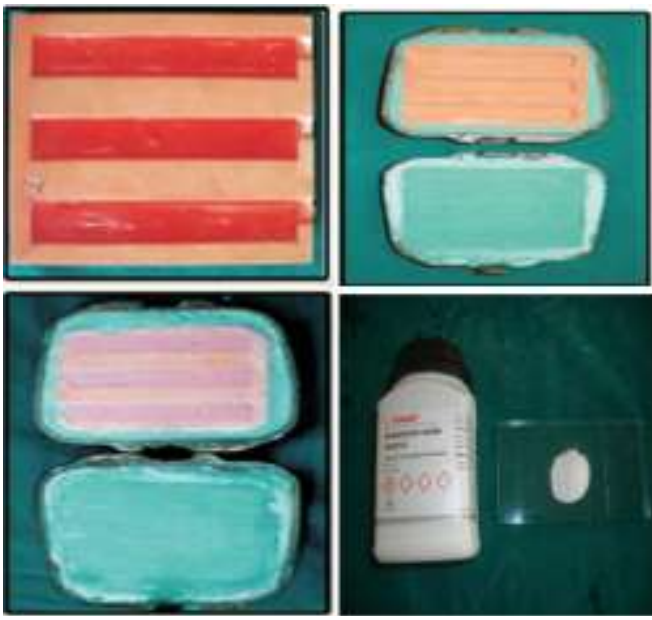

The flexural strength of the specimens were tested in universal testing machine.Load was applied at the center of the specimen at a cross head speed of $5 \mathrm{~mm} /$ minute, until it fractured. 

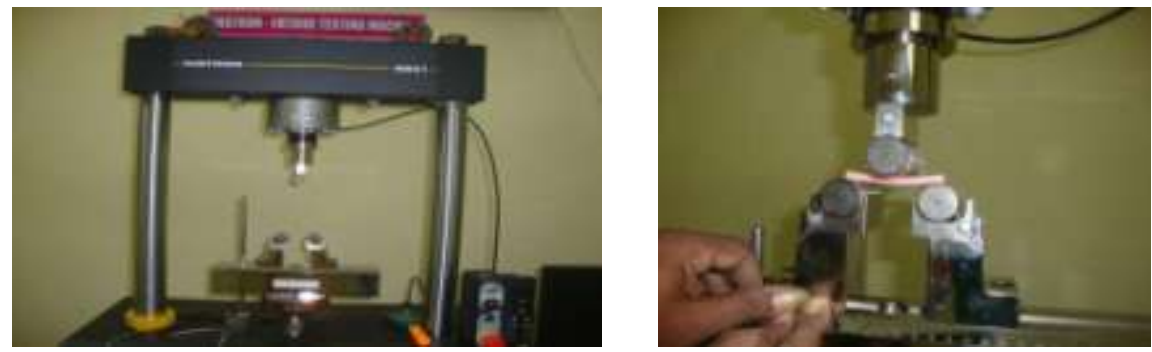

Fig E: Universal testing machine

For hardness testing, to determine Vickers values, a load of $30 \mathrm{~g}$ was applied for 30seconds to specimens using a digital hardness tester. Eachspecimen was subjected to three indentations (one at thecenter and two at the border), and the average value wascalculated for each group.
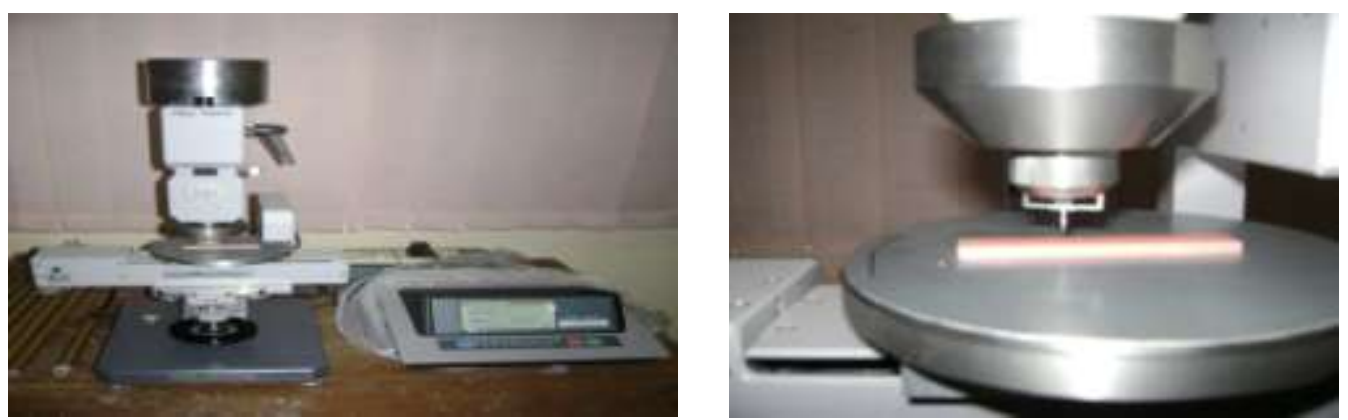

Fig F: Shore hardness tester

The values obtained were subjected to statistical analysisusing one way ANOVA followed by post hoc Tukey's test formultiple group comparison and paired ' $\mathrm{t}$ ' test for intra groupcomparisons.

\section{Results}

The mean flexural strength of DPI heat cure resin group A is 78.2 MPa,group B is 79.4 MPa, group C is 82.3 and group $\mathrm{D}$ is 82.37 .The mean flexural strength of LUCITONE heat cure resin:group A is $75.5 \mathrm{MPa}$, group B is $80.8 \mathrm{MPa}$,group C is $82.8 \mathrm{MPa}$ and group D is $83.4 \mathrm{MPa}$.Lucitone added with $15 \%$ aluminum oxide by wt. is found to have highest flexural strength.

Hardness of DPI heat cure resin group A is 65.5 MPa,group B is $73.3 \mathrm{MPa}$,group C is $85.8 \mathrm{MPa}$,group $\mathrm{D}$ is $91.1 \mathrm{MPa}$. The hardness of LUCITONE heat cure resin group A is $66.6 \mathrm{MPa}$,group B is $71.8 \mathrm{MPa}$,group C is $81.9 \mathrm{MPa}$,group D is $97.3 \mathrm{MPa}$.Hardness is also highest with lucitone added with $15 \%$ aluminum oxide powder.

Table 1 shows the flexural strength values of the groups.Table 2 shows the graphical representation of the flexural strength values.Table 3 shows the hardness values of the groups.Table 4 shows the graphical representation of the hardness values.Table 5 shows the comparison between DPI and LUCITONE heat cure resin materials.Table 6 shows the graphical representation of comparison between DPI and LUCITONE heat cure materials.

Table 1: Flexural strength values of the groups

\begin{tabular}{|c|c|c|c|c|c|c|}
\hline Groups & $n$ & Mean & SD & F-Value & P-Value & Decision \\
\hline CONTROL DPI & 9 & 78.22222 & 3.374455 & \multirow{8}{*}{16.216} & \multirow{8}{*}{0.000} & \multirow{8}{*}{ Significant } \\
\hline AL2O3 5\%+DPI & 9 & 79.47778 & 2.133529 & & & \\
\hline AL203 10\%+DPI & 9 & 82.3 & 0.947365 & & & \\
\hline AL20 15\%+DPI & 9 & 82.37778 & 1.428966 & & & \\
\hline CONTROL+LUCITONE & 9 & 75.58889 & 2.731503 & & & \\
\hline AL203 5\%+LUCITONE & 9 & 80.85556 & 2.010666 & & & \\
\hline AL2O3 10\%+ LUCITONE & 9 & 82.85556 & 1.048941 & & & \\
\hline AL2O3 15\%+ LUCITONE & 9 & 83.45556 & 1.048941 & & & \\
\hline
\end{tabular}


Table 2: Graphical representation of the flexural strength values

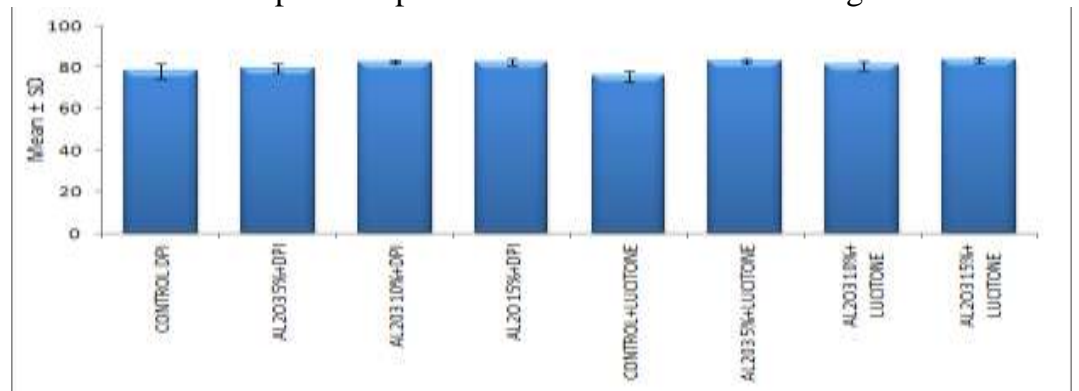

Table 3: Hardness values of different groups

\begin{tabular}{|c|c|c|c|c|c|c|}
\hline Groups & $n$ & Average & SD & F-Value & P-Value & Decision \\
\hline CONTROLDPI & 9 & 65.05556 & 8.919236 & \multirow{8}{*}{17.695} & \multirow{8}{*}{0.000} & \multirow{8}{*}{ Significant } \\
\hline AL2O3 5\% + DPI & 9 & 73.31111 & 3.917092 & & & \\
\hline AL2O3 10\%+DPI & 9 & 85.85556 & 11.75001 & & & \\
\hline AL2O3 15\%+DPI & 9 & 91.17778 & 13.61716 & & & \\
\hline CONTROLLUCITONE & 9 & 66.63333 & 8.039745 & & & \\
\hline AL2O3 5\%+LUCITONE & 9 & 71.81111 & 4.929869 & & & \\
\hline AL2O3 10\%+LUCITONE & 9 & 81.91111 & 4.868892 & & & \\
\hline AL2O3 15\%+LUCITONE & 9 & 97.36667 & 5.84658 & & & \\
\hline
\end{tabular}

Table 4: Graphical representation of hardness values

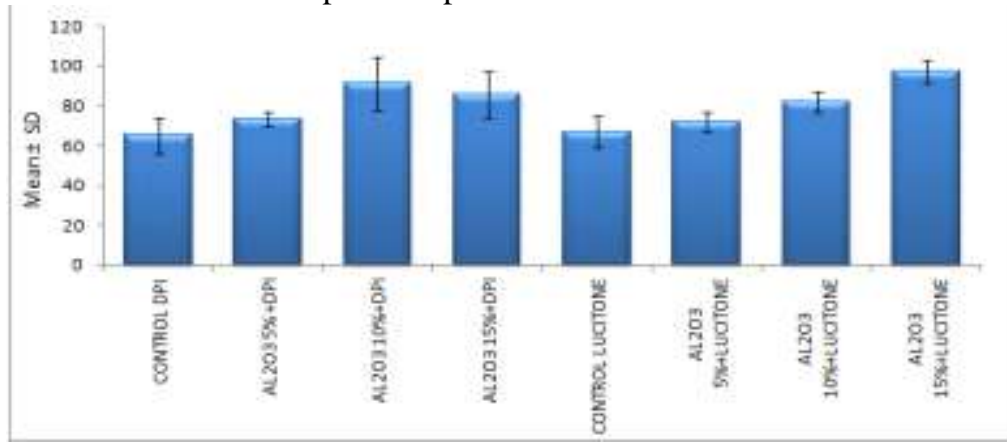

Table 5: Comparison between Lucitone and DPI heat cure materials

\begin{tabular}{|c|c|c|c|c|c|c|c|}
\hline & & N & Mean & SD & T.Value & P.Vaue & Decision \\
\hline \multirow[t]{2}{*}{ Hordness } & DPI & 36 & 80,5944 & 277660 & \multirow[t]{2}{*}{-0.125} & \multirow[t]{2}{*}{0.9011} & Not \\
\hline & LUCTONE & 36 & 80,6099 & 3,6060 & & & Ant \\
\hline 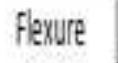 & DPI & 36 & 78.85 & 14,29 & \multirow[t]{2}{*}{-0179} & \multirow[t]{2}{*}{0.8585} & \\
\hline Strength & WUTTONE & 36 & 79,43 & 13.23 & & & \\
\hline
\end{tabular}

Table 6: Graphical representation to compare Lucitone and DPI heat cure materials

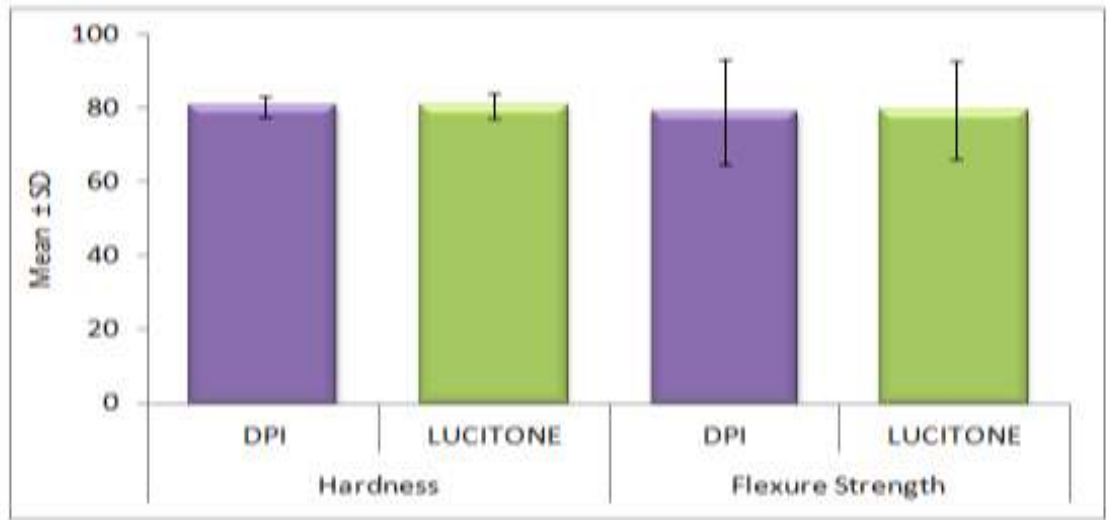




\section{Discussion}

The ultimate flexural strength of a material reflects its potentialto resist catastrophic failure under a flexural load. As a foundation, the acrylic resinmaterials should exhibit a high proportional limit to resist plasticdeformation and also exhibit fatigue resistance to endure

repeated masticatory loads(14-16).The denture base in a removable prosthesis with highflexural strength, flexural modulus, and a large yield pointdistance would help to resist torsional forces in function, leading to a longer clinical service life for the prosthesis. Carbon fibers have been added to the resin matrix andhave proved to be successful in increasing the strength of the

denture base(8). Despite producing successful reinforcement, theblack colour the fibers impart to the resin can be unacceptable tosome denture wearers.

Mullarky RH (17)studied the reinforcement of acrylic resin with aramid fibers. He was successful in enhancing the fatigue resistance of thearamid fiber reinforced acrylic resin denture base material.The yellow appearance of the fibers was difficultto mask within the denture, necessitating thick layers of acrylicresin that added significantly to the bulk of the denture.

MahrooVojdani, RafatBagheri(18) conducted a study which showed that addition of $2.5 \mathrm{wt} \%$ of untreated $\mathrm{Al} 2 \mathrm{O} 3$ to a conventional heat-curedresin improved the mechanical properties of PMMAwithout essential additional processing steps. Therefore,the fabrication of dentures by this method is not timeconsuming,which would encourage its routine use indental laboratories due to its low cost and ease of handlingand processing.Ellakwa(12) and colleagues havereported that reinforcing high-impact acrylic resin with untreated $\mathrm{Al} 2 \mathrm{O} 3$ powder at concentrationsof 5-20 wt\% resulted in increases in both the flexural strength andthermal diffusivity of this high-impact acrylic resins. Their study also showed that the hardness increased in proportion tothe weight percentage of the $\mathrm{Al} 2 \mathrm{O} 3$ filler. The hardnesssignificantly increased after incorporating 2.5 and $5 \mathrm{wt} \% \mathrm{Al} 2 \mathrm{O} 3$.

This finding is in agreement with previous investigators, who have concluded that reinforcing dentalrestorative resins and acrylic resin with ceramic particlescan produce some improvements in the surface hardness $(4,5,19,20)$. This increase in hardness may have been due to inherentcharacteristics of the Al2O3 particles. Al2O3 possesses strongionic interatomic bonding, giving rise to its desirablematerial characteristics, that is, hardness and strength $(19,21)$.

Aluminum oxide, commonly referred to as alumina has highhardness, excellent dielectric properties, refractoriness, and goodthermal properties make it the material of choice for a wide rangeof applications. Further more, the white colour of aluminum oxide powder is not expected to affect adversely the esthetic appearance of denture base resins.

\section{Conclusion}

Flexural strength of conventional high impact heatcure denture base resin (group-A) increased with addition ofincreased percentage of aluminum oxide powder. Incorporation of $5 \%$ by wt. aluminum oxide powderto heat cure denture base resin (group-B) did not producesignificant increase in flexural strength of conventional dentureresin (group-A). Incorporation of 10\% (group-C) and 15\% (group-D)by wt. aluminum oxide powder to heat cure denture base resin significantly increased the flexural strength of denture baseresin. Highest flexural strength was found with $15 \%$ by wt.incorporation of aluminum oxide powder to heat cure denturebase resin (group-D).

Hardness increased with addition of increased percentage of aluminum oxide powder.Lucitone added with $15 \%$ by weight aluminum oxideis found to have the highest hardness values.

\section{References}

[1]. Meng TR LM. Physical properties of four acrylic denture base resins. . J Contemp Dent Pract. 2005;6:93-100.

[2]. Sehajpal SB SV. Effect of fillers on some physical properties of acrylic resin. J Prosthet Dent 1986;61:746-51.

[3]. Dabbar UR HR, Harrison A. . Denture fracture-survey. . Br Dent J 1994;176:342-5.

[4]. Asar NV AH, Korkmaz T, Turkylmaz I. Influence of various metal oxides on mechanical and physical properties of heat-cured polymethyl methacrylate denture base resins. Journal Adv Prosthodont. 2013;5(3):241-7.

[5]. AR. R. Effect of steel strengtheners on fracture resistance of the acrylic resin complete denture base. . J Prosthet Dent. $1985 ; 54: 75-8$.

[6]. Carroll CE VFJ. Wire reinforcement of acrylic resin prostheses. . J Prosthet Dent 1984;52:639-41.

[7]. Jagger DC HA, Jandt KD. . Review: The reinforcement of dentures. J Oral Rehabil 1999;26:185-94.

[8]. DeBoer J VS, Brady RE. . The effect of carbon fiber orientation on the fatigue resistance and bending properties of two denture resins. . J Prosthet Dent 1984;51:119-21.

[9]. JF. RM. Impact strength of acrylic resin denture base materials with surface detects. . Dent Mater 1993;9:355-60.

[10]. Johnston EP NJ, Smith DE. . Flexural fatigue of 10 commonly used denture base resins. . J Prosthet Dent. 1981;48:478-83.

[11]. Alhareb AO AZ. Effect of Al2O3/ZrO2 reinforcement on the mechanical properties of PMMA denture base. . J Reinf Plast Compos 2011;30:83-5

[12]. Ellakwa AE MM, El-Sheik AM. Effect of Aluminum Oxide Addition on the Flexural Strength and Thermal Diffusivity of HeatPolymerized Acrylic Resin. Journal of Prosthodontics. 2008;17(6):439-44. 
[13]. Arora P SS, Arora V. Effect of Alumina Addition on Properties of Poly - methyl methacrylate - A Comprehensive Review. International Journal of Biotech Trends and Technology 2015;9(1):1-7.

[14]. KJ. A. Philips science of dental material. . 11th ed Middle East and African ed 2008. :p. 143-66, $721-56$.

[15]. Jagger DC JR, Allen SM, Harrison A. . An investigation into the transverse and impact strength of high strength denture base acrylic resins. J Oral Rehabil. 2002;29(3):263-7.

[16]. Jasim BS II. The effect of silanized alumina nano -fillers addition on some physical and mechanical properties of heat cured polymethyl methacrylate denture base material. Journal of Bagh College Dentistry. 2014;26(2):18-23.

[17]. RH. M. Aramid fiber reinforcement of acrylic appliances. . J Clin Orthod 1985;19:655-8.

[18]. Vojdani M BR, Khaledi AAR. Effects of aluminum oxide addition on the flexural strength, surface hardness, and roughness of heatpolymerized acrylic resin. Journal of Dental Sciences. 2012;7:238-44.

[19]. Vallittu PK LV. Effect of metal strengthener's surface roughness on fracture resistance of acrylic denture base material. J Oral Rehabil 1992;19:385-91.

[20]. Korkmaz T DaA, Usanmaz A. . Dynamic mechanical analysis of provisional resin materials reinforced by metal oxides. . Biomed Mater Eng 2005;15:179-88.

[21]. Saritha M.K SS, Nandeeshwar D.B, Tewary S. An in vitro study to investigate the flexural strength of conventional heat polymerised denture base resin with addition of different percentage of aluminium oxide powder. Asian J Med Cli Sci. $2012 ; 1(2): 80-5$ 